\title{
Engulfment signals and the phagocytic machinery for apoptotic cell clearance
}

\author{
Seung-Yoon Park ${ }^{1,2}$ and In-San Kim ${ }^{2,3}$
}

The clearance of apoptotic cells is an essential process for tissue homeostasis. To this end, cells undergoing apoptosis must display engulfment signals, such as 'find-me' and 'eat-me' signals. Engulfment signals are recognized by multiple types of phagocytic machinery in phagocytes, leading to prompt clearance of apoptotic cells. In addition, apoptotic cells and phagocytes release tolerogenic signals to reduce immune responses against apoptotic cell-derived self-antigens. Here we discuss recent advances in our knowledge of engulfment signals, the phagocytic machinery and the signal transduction pathways for apoptotic cell engulfment.

Experimental \& Molecular Medicine (2017) 49, e331; doi:10.1038/emm.2017.52; published online 12 May 2017

Several billion senescent or damaged cells in the body physiologically undergo apoptosis every day. Rapid removal of apoptotic cells from tissues is important for maintaining tissue homeostasis and preventing inappropriate inflammatory responses in multicellular organisms. During this process, apoptotic cells express engulfment signals such as 'find-me' and 'eat-me' signals that indicate they should be removed from tissues, and phagocytes engulf apoptotic cells using multiple types of phagocytic machinery. At this point, apoptotic cell phagocytosis is distinguished from other types of phagocytosis and is designated 'efferocytosis' ('effero' means 'to carry to the grave'). ${ }^{1}$ This review focuses on several recent advances in our understanding of engulfment signals, the phagocytic machinery and signal transduction during efferocytosis.

\section{ENGULFMENT SIGNALS}

'Find-me' signals

Cells undergoing apoptosis secrete molecules, so-called 'find-me' signals (also referred to as 'come-to-get-me' signals), to attract phagocytes toward them. To date, four representative 'find-me' signals have been identified, including lysophosphatidylcholine (LPC), sphingosine-1-phosphate (S1P), CX3C motif chemokine ligand 1 (CX3CL1, also referred to as fractalkine), and nucleotides (ATP and UTP; Figure 1). LPC is released from apoptotic cells and binds to the G-protein-coupled receptor G2A on macrophages, facilitating the migration of macrophages to apoptotic cells. ${ }^{2}$ In apoptotic cells, caspase-3 activation induces cleavage and activation of calcium-independent phospholipase A2 (iPLA2; also referred to as PLA2G6), which in turn processes phosphatidylcholine into LPC. ${ }^{3}$ Recently, ATP-binding cassette transporter A1 (ABCA1) was shown to be required for the release of LPC from apoptotic cells. ${ }^{4}$ CX3CL1 is generated as a membrane-associated protein and then released from apoptotic cells by proteolytic processing. ${ }^{5}$ The secreted CX3CL1 binds to CX3C motif chemokine receptor 1 (CX3CR1) on microglia and macrophages, resulting in the migration of phagocytes. However, the roles of LPC and CX3CL1 as 'find-me' signals have not been clarified in an in vivo animal model. S1P is generated from sphingosine by sphingosine kinase. It is secreted by dying cells in a caspase-3dependent manner and binds to S1P receptors on macrophages, leading to the recruitment of macrophages to apoptotic cells. ${ }^{6}$ Nucleotides, including ATP and UTP, are released from apoptotic cells in a caspase-3-dependent manner and are sensed by purinergic receptors on phagocytes, resulting in the recruitment of phagocytes to apoptotic cells. ${ }^{7}$ The release of nucleotides from apoptotic cells is mediated by pannexin 1 channels, which are activated in apoptotic cells in a caspase-3-dependent manner. ${ }^{8}$ Although these molecules are defined as 'find-me' signals, many unanswered questions remain to be elucidated, including their reaction range, functional mode (cooperativity or redundancy) and in vivo relevance.

\footnotetext{
${ }^{1}$ Department of Biochemistry, School of Medicine, Dongguk University, Gyeongju, Republic of Korea; ${ }^{2}$ Center for Theragnosis, Biomedical Research Institute, Korea Institute Science and Technology, Seoul, Republic of Korea and ${ }^{3}$ KU-KIST School, Korea University, Seoul, Republic of Korea Correspondence: Professor S-Y Park, Department of Biochemistry, School of Medicine, Dongguk University, 123 Dongdae-ro, Gyeongju 780-714, Republic of Korea.

E-mail: psyoon@dongguk.ac.kr

or Professor I-S Kim, Biomedical Research Institute, Korea Institute Science and Technology, 5 Hwarang-ro 14-gil, Seoul 136-791, Republic of Korea. E-mail: iskim14@kist.re.kr

Received 6 December 2016; accepted 15 December 2016
} 


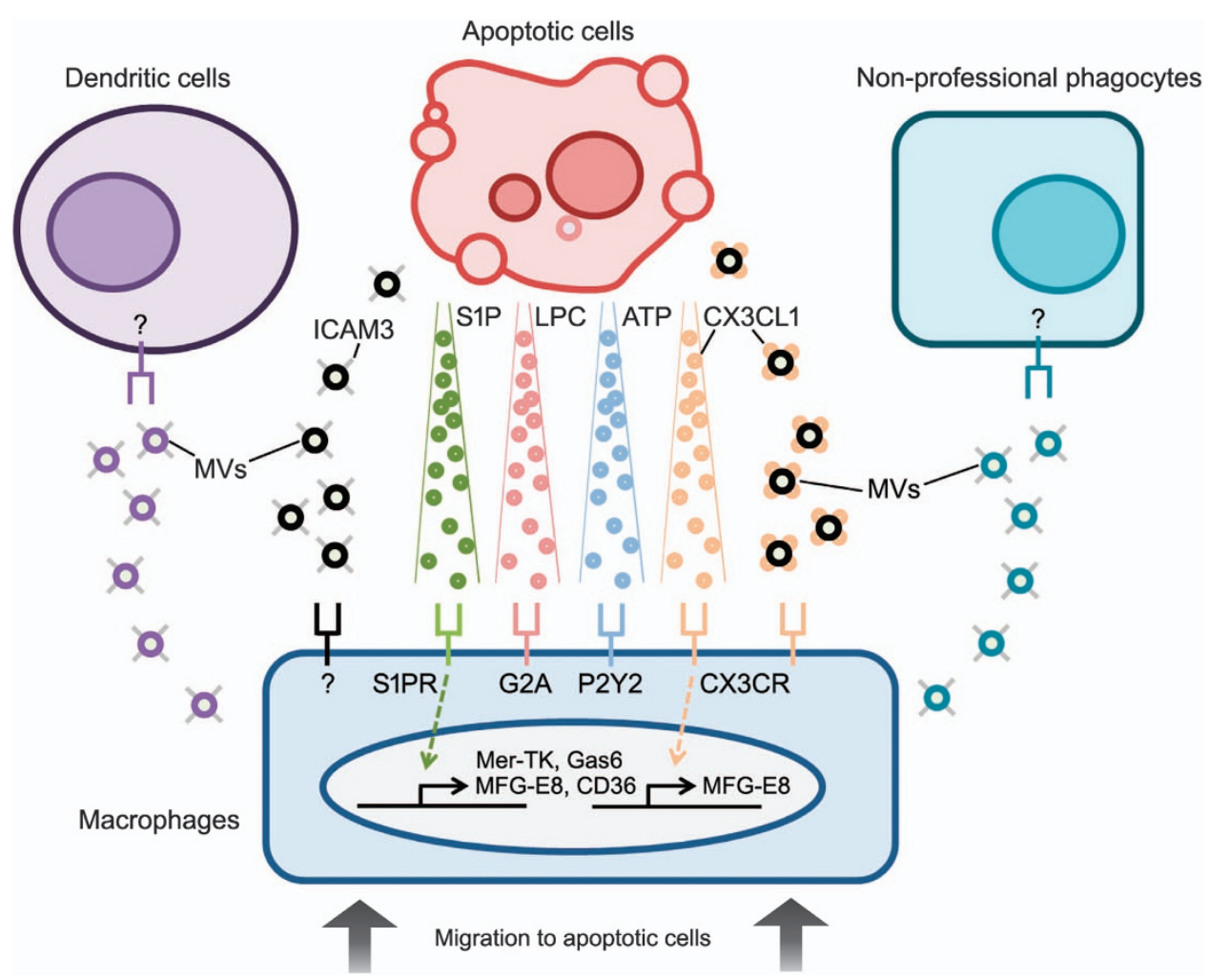

Figure 1 'Find-me' signals released by apoptotic cells and extracellular vesicles. Four representative 'find-me' signals released by apoptotic cells have been identified, including S1P (sphingosine-1-phosphate), LPC (lysophosphatidylcholine), nucleotides (ATP or UTP) and CX3CL1 (CX3C motif chemokine ligand 1; fractalkine). They bind to S1PR, G2A, P2Y2 and CX3CR, respectively, on the phagocyte surface, promoting phagocyte migration to apoptotic cells. Extracellular vesicles released by apoptotic cells and phagocytes appear to modulate functions of phagocytes during efferocytosis. Apoptotic cell-derived microparticles also attract macrophages to sites of cell death through CX3CL1 and ICAM3. Phagocyte-derived microvesicles and exosomes modulate phagocytic capacity in epithelial cells and the transfer of apoptotic cell-derived antigens to dendritic cells, respectively.

In addition, 'find-me' signals have multiple roles in efferocytosis. CX3CL1 appears to upregulate MFG-E8 expression in microglial cells and peritoneal macrophages. ${ }^{9,10}$ S1P released by apoptotic cells acts as an anti-apoptotic mediator and attenuates macrophage apoptosis, ${ }^{11}$ suggesting that apoptotic cells can prevent damage to neighboring cells to maintain tissue homeostasis. Recently, S1P has been shown to trigger the activation of erythropoietin (EPO)-EPO receptor (EPOR) signaling, which increases the expression of phagocytic receptors through peroxisome proliferator-activated receptor- $\boldsymbol{\gamma}^{12}$

\section{'Eat-me' signals}

Dying cells also express 'eat-me' signals on the cell surface to indicate they should be engulfed by macrophages (Figure 2). Although a variety of potential 'eat-me' signals have been proposed, the best-characterized 'eat-me' signal is the expression of phosphatidylserine on the cell surface. Phosphatidylserine is a plasma membrane phospholipid that is localized on the inner membrane leaflet of the lipid bilayer in healthy cells and externalized on the cell surface in response to apoptotic stimuli. ${ }^{13}$ The externalization of phosphatidylserine on the cell surface during apoptosis and its role in cell corpse clearance has also been identified in Caenorhabditis elegans and Drosophila. ${ }^{14,15}$
Recently, Xk-related protein 8 (Xkr8) has been shown to mediate surface expression of phosphatidylserine in apoptotic cells in a caspase-3-dependent manner. ${ }^{16}$ This process is also mediated by the Xkr8 ortholog CED-8 in Caenorhabditis elegans, indicating a conserved mechanism for apoptotic phosphatidylserine exposure. ${ }^{17}$ More recently, Xkr8 has been shown to associate with basigin or neuroplastin at the plasma membrane in response to apoptotic stimuli, and this complex is required for the proper scrambling activity of $\mathrm{Xkr8}{ }^{18}$ In addition, the P-type ATPase ATP11C acts as a flippase to transport aminophospholipids from the outer leaflet to the inner leaflet of the lipid bilayer to maintain membrane asymmetry. In cells undergoing apoptosis, it is inactivated by caspase-3-mediated cleavage, permitting phosphatidylserine externalization. ${ }^{19}$

Calreticulin (CRT) is another potential 'eat-me' signal expressed on the apoptotic cell surface. In dying cells induced by endoplasmic reticulum (ER) stress, activated protein kinase RNA-like ER kinase phosphorylates eIF2 $\alpha$, which induces caspase- 8 activation, Bap31 cleavage and Bax activation, resulting in the translocation of CRT from the ER to the Golgi and SNARE-mediated exocytosis. ${ }^{20}$ CRT on the apoptotic cell surface is sensed by low-density lipoprotein receptor-related protein (also referred to as CD91) on phagocytes to promote 


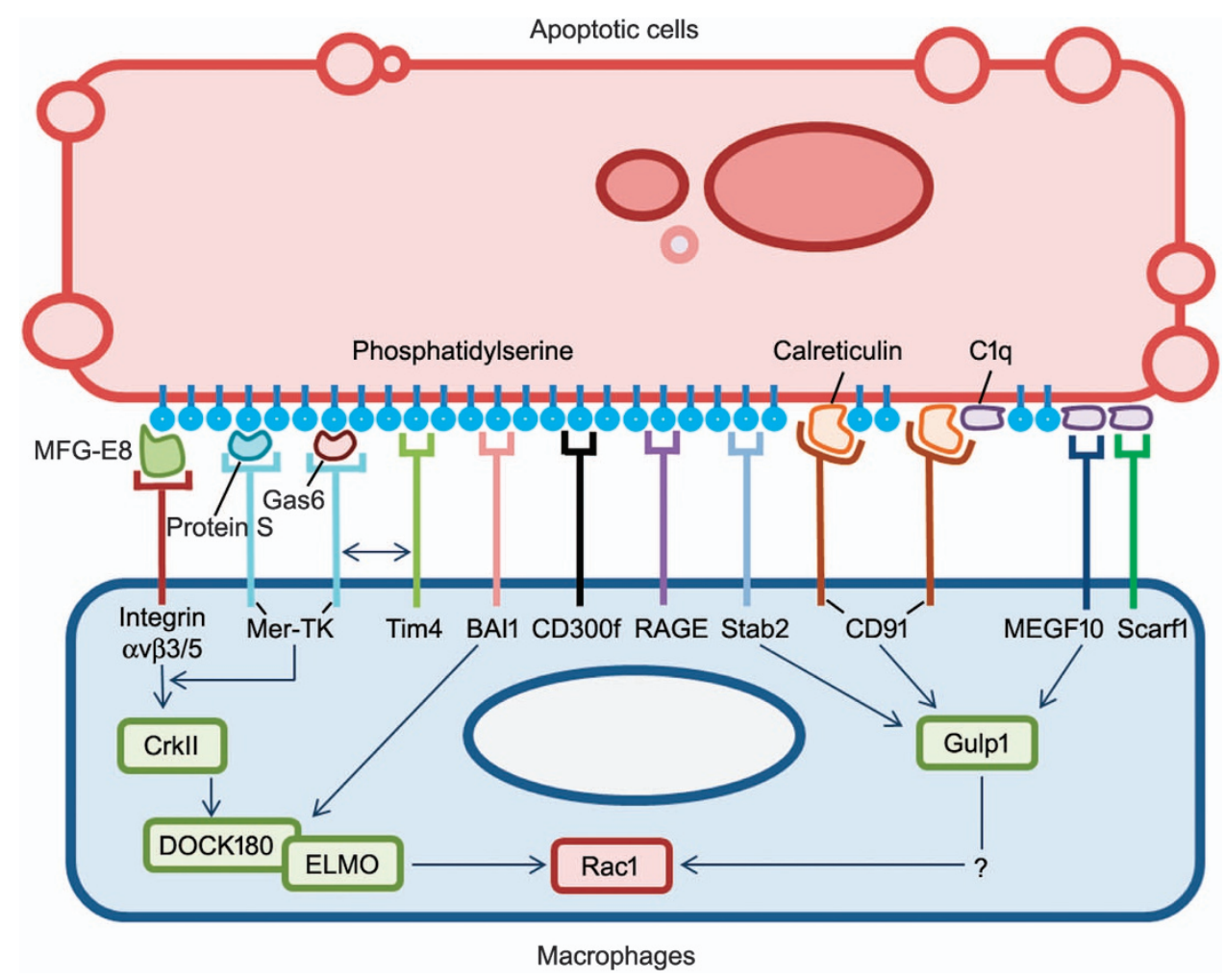

Figure 2 'Eat-me' signals, phagocytic machinery and signaling pathways. Apoptotic cells express 'eat-me' signals, such as phosphatidylserine and calreticulin, on the cell surface in response to apoptotic stimuli. Exposed phosphatidylserine on the apoptotic cell surface is recognized directly by phosphatidylserine receptors (Tim family proteins, BAI1, Stabilin-2, CD300f and RAGE) or indirectly by bridging molecules (MFG-E8, Gas6, protein $S$ and C1q). MFG-E8 bound to phosphatidylserine is recognized by integrin $\alpha v \beta 3 / 5$ on the phagocytes, and Gas6 or protein S bound to phosphatidylserine is sensed by Mer-TK. Bridging molecule C1q is recognized by MEGF10 or scarf1. Another 'eat-me' signal, calreticulin, is associated with phosphatidylserine or $\mathrm{Clq}$ on the apoptotic cell surface and recognized by CD91 (LRP1). Integrin $\alpha v \beta 3 / 5$ and BAI transduce signals for cytoskeletal rearrangement through DOCK180/ELMO1, whereas Stabilin-2, MEGF10 and CD91 use adaptor protein Gulp1 as an engulfment signaling pathway.

engulfment. ${ }^{21}$ Recently, CRT is shown to bind to phosphatidylserine via its C-terminal acidic region, leading to apoptotic cell phagocytosis. ${ }^{22}$ Furthermore, phagocytosis of cells expressing CRT on the cell surface appears to induce immunogenic responses, ${ }^{23}$ suggesting that recognition of CRT by specific phagocytes, especially dendritic cells, might trigger immunogenic signals rather than self-tolerance signals. However, it is unclear whether recognition of CRT is sufficient to trigger a signal to induce immunogenic responses in phagocytes (macrophages and dendritic cells). CRT is also expressed on the cell surface of macrophages through TLR and Btk signaling, stimulating cancer cell phagocytosis. ${ }^{24}$ It is therefore possible that CRT is a PS-binding bridging molecule released from apoptotic cells and phagocytes rather than an 'eat-me' signal.

In addition to the role of phosphatidylserine as an 'eat-me' signal, the recognition of phosphatidylserine by phagocytes can enhance cholesterol efflux from cells to maintain cellular homeostasis ${ }^{25}$ and trigger release of anti-inflammatory cytokines to induce immunogenic tolerance for apoptotic cell-derived antigens. ${ }^{26}$ These findings suggest that phosphatidylserine exposure is not only an 'eat-me' flag to detect apoptotic cells but also a trigger of endogenous signaling for cellular homeostasis in phagocytes. However, the molecular details of phosphatidylserine-mediated signaling remain to be clarified further.

\section{'Don't eat-me' signals}

Healthy cells display 'don't eat-me' signals, such as CD47 and CD31, on the cell surface to avoid efferocytosis. CD47 (also referred to as integrin-associated protein) is a membrane protein composed of an immunoglobulin (Ig) domain, five membrane-spanning regions and cytoplasmic region. Oldenborg et al. ${ }^{27}$ found that CD47-deficient erythrocytes injected into mice are more rapidly removed by splenic macrophages than are CD47-positive erythrocytes. They suggested that CD47 functions as a signal for discrimination between self and non-self. In healthy cells, CD47 interacts with signal regulatory protein alpha (SIRP $\alpha$; also referred to as SHPS-1 and CD172a) on macrophages. The CD47-SIRP $\alpha$ interaction induces tyrosine phosphorylation of the immunoreceptor tyrosinebased inhibitory motif in the SIRP $\alpha$ cytoplasmic tail and subsequent recruitment and activation of the inhibitory tyrosine phosphatases SHP-1 and SHP-2, resulting in the negative regulation of actin cytoskeletal rearrangement for phagocytosis. Senescent or damaged cells exhibit decreased CD47 expression or an altered pattern of CD47 distribution, 
thereby permitting efferocytosis. ${ }^{21,28}$ Several cancer cell types, such as circulating leukemic stem cells and acute myeloid leukemia, were found to highly express CD47 on their surface to evade immune cells. ${ }^{29,30}$ Recent studies showed that a neutralizing CD47 antibody or soluble SIRP $\alpha$ variants promote tumor cell engulfment by macrophages and suppress tumor growth in in vivo tumor models. ${ }^{31-33}$

Another candidate 'don't eat-me' signal is CD31 (also referred to as platelet and endothelial cell adhesion molecule 1). A CD31-CD31 homotypic interaction between viable neutrophils and phagocytes acts as a repulsive signal, thereby mediating detachment of viable cells from phagocytes. In contrast, apoptotic cells do not trigger this repulsive signal and are efficiently engulfed by phagocytes. ${ }^{34}$ However, the intracellular signaling pathways for $\mathrm{CD} 31$-mediated repulsion remain to be clarified.

\section{Extracellular vesicles}

Almost all cells release membrane vesicles, which play an important role in intercellular communications. ${ }^{35}$ Apoptotic cells can mediate the recruitment of phagocytes through the release of microparticles (Figure 1). ICAM-3 in apoptotic cell-derived microparticles induces the migration of macrophages towards apoptotic cells. ${ }^{36}$ CX3CL1-positive microparticles are shown to induce the recruitment of macrophages to apoptotic cells. ${ }^{37}$ Adipocyte-derived microparticles are released in a caspase- 3 and Rho-kinase-dependent manner and facilitate microphage migration to obese adipose tissues. ${ }^{38}$ Recently, microparticles released from apoptotic cells have been shown to induce immune responses to apoptotic cell-derived antigens in the presence of IFN- $\alpha .{ }^{39}$ Chromatin on the apoptotic cell surface appears to be a self-antigen that triggers immunogenic responses. ${ }^{40}$ Thus, microparticles elicited from apoptotic cells might be removed to maintain tissue homeostasis and prevent aberrant inflammation. However, the clearance mechanism of apoptotic cell-derived microparticles remains to be investigated.

Phagocytes also appear to emit microparticles. ${ }^{41}$ Recent studies showed that macrophages can communicate with other professional or nonprofessional phagocytes through the release of extracellular vesicles (Figure 1). Insulin-like growth factor-1 (IGF-1) released from macrophages promotes the engulfment of macrophage-derived microvesicles by epithelial cells, leading to reduced inflammatory responses in epithelial cells. ${ }^{42}$ Macrophages are capable of transferring dead-cell-associated antigens to dendritic cells through the release of exosomes in a ceramide-dependent manner. ${ }^{43}$ These observations suggest that microvesicles derived from apoptotic cells or phagocytes can modulate efferocytosis.

\section{TOLEROGENIC SIGNALS}

In the absence of infection or inflammation, apoptotic cell clearance is immunogenically silent. At this point, apoptotic cells and phagocytes might express signals to suppress the immune response to self-antigens. Apoptotic cells release signals to inhibit the recruitment of inflammatory cells, known as 'keep out' or 'stay away' signals. Lactoferrin is expressed in response to apoptotic stimuli and selectively inhibits the migration of granulocytes (neutrophils and eosinophils) but not monocytes and macrophages. ${ }^{44,45}$ However, the role of lactoferrin in the negative regulation of the migration of inflammatory cells requires clarification in an in vivo animal model.

Annexin A1 was originally defined as an engulfment signal for the efficient clearance of apoptotic cells. ${ }^{46}$ Annexin A1 on the apoptotic cell surface is known to inhibit dendritic activation, which in turn inhibits inflammatory cytokines and T-cell activation for apoptotic cell-derived antigens. ${ }^{47}$ Annexins A5 and A13 also suppress dendritic cell activation for apoptotic cell-derived antigens, resulting in immunogenic tolerance. ${ }^{48}$ However, deficiency in individual annexins did not show an obvious phenotype such as autoimmunity, suggesting that annexin proteins may have a redundant function. Thus, it remains to be defined whether annexin proteins are tolerogenic factors to suppress immune responses for apoptotic cellderived antigens.

The 12/15-lipoxygenase in resident peritoneal macrophages causes the cell surface exposure of oxidized phosphatidylethanolamine, which sequesters the MFG-E8 required for the clearance of apoptotic cells in inflammatory monocytes, suggesting that oxidized phosphatidylethanolamine on resident macrophages may be a signal to reduce immune responses. ${ }^{49}$ Recently, the chromatin on microparticles secreted from apoptotic cells was shown to be a self-antigen that induces immunogenic responses. In this context, DNase1L3 produced by macrophages and dendritic cells digests chromatin in apoptotic cell-derived microparticles, ${ }^{40}$ suggesting that secreted DNase1L3 is a molecular mechanism for achieving immune tolerance for apoptotic cell-associated antigens.

\section{PHAGOCYTIC MACHINERY}

Phagocytes can recognize phosphatidylserine on the apoptotic cell surface through two types of phosphatidylserine recognition machinery: phosphatidylserine receptors and soluble bridging molecules. Phosphatidylserine receptors on the surface of phagocytes directly bind to phosphatidylserine on apoptotic cells, whereas soluble bridging molecules recognize phosphatidylserine on the apoptotic cell surface and function as a bridge between apoptotic cells and cell surface receptors on phagocytes (Figure 2).

\section{Phosphatidylserine receptors}

T-cell immunoglobulin and mucin domain-containing molecule (Tim) family proteins, Tim-1 (also referred to as kidney injury molecule 1 (Kim-1)), Tim-3 and Tim-4, act as phosphatidylserine receptors to clear apoptotic cells. ${ }^{50-52} \mathrm{Tim}-1$ and Tim-4 bind to phosphatidylserine through a metal-iondependent ligand-binding site in their immunoglobulin $\mathrm{V}$ domain. ${ }^{53}$ Tim-1 is highly expressed in damaged kidney epithelial cells and confers phagocytic capacity to them. ${ }^{54}$ Tim-1-mediated efferocytosis is responsible for protecting the kidney after acute injury through PI3K-dependent 
downregulation of NF- $\kappa \mathrm{B} .{ }^{55} \mathrm{Tim}-3$ is expressed in peritoneal exudate cells and CD8-positive dendritic cells and contributes to the clearance of apoptotic cells and cross-presentation of apoptotic cell-associated antigens. ${ }^{52}$ Tim- 4 is expressed by professional phagocytes (macrophages and dendritic cells) and controls phosphatidylserine-dependent efferocytosis and adaptive immunity. ${ }^{50,56}$ However, Tim-4 does not seem to transduce a signal for engulfment, which suggests that Tim-4 functions as a tethering receptor to recognize phosphatidylserine on the apoptotic cell surface and may be required for other proteins to trigger internalization of apoptotic cells. ${ }^{57}$ Indeed, recent studies identified that Mer-TK and integrin $\beta 1$ act as partners to transduce signals after Tim-4-mediated phosphatidylserine recognition. ${ }^{58,59}$

Brain-specific angiogenesis inhibitor 1 (BAI1) is a member of the G-protein-coupled receptor family; it has seven transmembrane regions and binds to phosphatidylserine through its thrombospondin type 1 repeats. ${ }^{60}$ BAI1 interacts with the DOCK180/ELMO1 complex through an $\alpha$-helical region in its cytoplasmic tail, thereby providing the signal for Racl activation. However, BAI1 is predominantly expressed in neuronal cells of the cerebral cortex, ${ }^{61}$ suggesting that its role may be tissue-specific. Recently, BAI1 is known to contribute to phagosome formation and transport during the phagocytosis of apoptotic neurons by microglial cells. ${ }^{62}$ In skeletal muscle, BAI1 and its homologous protein BAI3 bind to apoptotic myoblasts and transduce signals to fuse myoblasts. ${ }^{63,64}$

Stabilin-2 (also referred to as hyaluronic acid receptor for endocytosis (HARE) and FEEL-2) is a large membrane protein that is composed of seven FAS1 domains, eight atypical epidermal growth factor (EGF)-like domains, fifteen EGF-like domains, a Link domain, a transmembrane region and a cytoplasmic domain. ${ }^{65}$ Stabilin-2 binds to phosphatidylserine via its EGF-like domain repeats, promoting apoptotic cell engulfment. ${ }^{66}$ The histidine residue in the PS-binding loops is conserved in four EGF-like-domain repeats and plays an important role in $\mathrm{pH}$-dependent phagocytic activity. ${ }^{67}$ Stabilin1 (also referred to as CLEVER-1 and FEEL-1), a homologous protein of stabilin-2, mediates apoptotic cell engulfment through phosphatidylserine recognition. ${ }^{68}$ Stabilin-1 and -2 are expressed in sinusoidal endothelial cells and macrophages. ${ }^{65,69-71}$ In hepatic endothelial cells, they act as tethering receptors for the capture of phosphatidylserineexposed damaged erythrocytes through phosphatidylserine recognition. ${ }^{72}$ However, the functions of stabilin- 1 and -2 on efferocytosis require clarification in a knockout mouse model.

CD300 family proteins, including CD300b and CD300f, have recently been shown to act as phosphatidylserine recognition receptors to clear apoptotic cells. ${ }^{73,74}$ CD300f regulates the engulfment of apoptotic cells via the PI3K pathway, leading to the activation of Rac1/Cdc42 GTPases to regulate F-actin. ${ }^{75} \mathrm{CD} 300 \mathrm{~b}$ is associated with DAP12 through its ITAM motif and activates the PI3K/Akt pathway. ${ }^{73}$ In contrast, another CD300 family protein, CD300a, inhibits the uptake of apoptotic cells through binding to phosphatidylserine and phosphatidylethanolamine. ${ }^{76}$ How the recognition of phosphatidylserine by CD300 family proteins induces stimulatory and inhibitory signals for apoptotic cell removal remains to be investigated.

Receptor for advanced glycation end products (RAGE) also binds to phosphatidylserine and has a role in the clearance of apoptotic cells. ${ }^{77}$ RAGE is a type I membrane protein that belongs to the immunoglobulin protein family and specifically binds to phosphatidylserine. However, various soluble forms of RAGE also bind to phosphatidylserine on the apoptotic cell surface, thereby preventing apoptotic cell engulfment by phagocytic receptors. The physiological role of soluble RAGE proteins remains to be studied. In addition, several scavenger receptors have been proposed as receptors for apoptotic cell clearance, including CD36 and CD14. CD36 associates with integrin to engulf apoptotic cells in a thrombospondin-dependent manner and directly binds to oxidized phosphatidylserine. ${ }^{78,79}$ CD14 has been proposed to be a receptor for apoptotic cell engulfment. ${ }^{80}$ Studies of CD14-deficient mice showed that CD14 is a tethering receptor but not an engulfment receptor for apoptotic cells. ${ }^{81}$

\section{Bridging molecules that recognize phosphatidylserine}

Several soluble proteins have been identified as bridging molecules that recognize the 'eat-me' signals on the surface of apoptotic cells, including milk fat globule EGF factor 8 (MFG-E8, also referred to as lactadherin), growth arrestspecific 6 (Gas6), protein S and C1q. They bind to both phosphatidylserine on the apoptotic cell surface and phagocytic receptors on phagocytes, providing a link between apoptotic cells and phagocytes. MFG-E8 secreted by macrophages and immature dendritic cells binds to phosphatidylserine on apoptotic cells through its $\mathrm{C} 1$ and $\mathrm{C} 2$ domains and interacts with $\alpha v \beta 3$ or $\alpha v \beta 5$ integrin on phagocytes through the RGD (Arg-Gly-Asp) motif in its EGF domain, resulting in the promotion of apoptotic cell phagocytosis. ${ }^{82,83}$ Gas6 and protein $\mathrm{S}$ share a similar domain structure and bind to phosphatidylserine on apoptotic cells to promote efferocytosis. ${ }^{84,85}$ They are composed of a Gla domain at the $\mathrm{N}$ terminus, four EGF-like domains, and two laminin G-like domains at the $\mathrm{C}$ terminus. They bind to phosphatidylserine in a calcium-dependent manner via their Gla domain and associate with Tyro3-AxlMer (TAM) family tyrosine-kinase receptors on phagocytes through laminin G-like domains. ${ }^{86,87}$

Mer tyrosine kinase (Mer-TK) is the best-characterized TAM receptor and is known to transduce an important signal for apoptotic cell engulfment. ${ }^{88}$ Mer-TK signaling is functionally associated with multiple engulfment systems for the efficient removal of apoptotic cells. Signaling from Mer-TK is induced by binding to Gas6 and functionally associated with $\alpha v \beta 5$ integrin-mediated signaling. ${ }^{89}$ Scavenger receptor A (SR-A) associates with Mer-TK to transduce signals during apoptotic cell engulfment. ${ }^{90}$ Galectin-3 was found to be a new ligand of Mer-TK for apoptotic cell clearance. ${ }^{91}$ Mer-TK mediates signal transduction from Tim-4-mediated efferocytosis. ${ }^{58}$ Considering that Mer-TK plays a crucial role in inhibiting dendritic cell activation for apoptotic cellassociated antigens, ${ }^{92}$ it is possible that Mer-TK has a common 
role in multiple engulfment systems to regulate immune responses. Recently, the TAM receptor tyrosine kinases Mer-TK and Axl were shown to function as phagocytic receptors under different environments. Mer-TK is primarily expressed at steady-state or under immune suppressive conditions and maintains immune tolerance, whereas Axl is expressed in response to proinflammatory stimuli and suppresses immune responses. ${ }^{93}$

Another potential bridging molecule is C1q, the first component of complement, which binds to phosphatidylserine on the apoptotic cell surface. ${ }^{94} \mathrm{Clq}$ binds to apoptotic cells likely via its globular head and interacts with calreticulin-CD91 on phagocytes to promote apoptotic cell engulfment. ${ }^{95}$ SCARF1 (also referred to as scavenger receptor expressed by endothelial cell 1) acts as a receptor that recognizes $\mathrm{Clq}$ bound to apoptotic cells. ${ }^{96}$ Recently, MEGF10 has also been shown to mediate apoptotic neuron clearance by astrocytes through bridging molecule C1q. ${ }^{97}$ Furthermore, the activation of macrophages by $\mathrm{C} 1 \mathrm{q}$ regulates Mer-TK and Gas6 expression. ${ }^{98}$

\section{Possible link between many engulfment signals and the phagocytic machinery}

Why are multiple phagocytic receptors necessary for efficient efferocytosis? Such multiple apoptotic cell recognition systems may be useful at several levels. First, discriminating dying cells from live cells during efferocytosis is important for proper cellular turnover. Although several 'eat-me' signals are present, there are many cases in which phosphatidylserine is substantially expressed on the cell surface of live cells, including cell-cell fusion, T-cell activation and platelet activation. ${ }^{99}$ It is possible that specificity for apoptotic cell recognition can be improved if multiple phagocytic receptors bind to specific 'eat-me' flags on the apoptotic cell surface, or that sufficient mechanical force for efferocytosis can be provided by multiple phosphatidylserine recognition systems. Second, the eating of apoptotic cells by macrophages requires various cellular events, including the tethering of apoptotic cells on phagocytes, cytoskeletal rearrangement for internalization, suppression of immune responses, and disposal of metabolic burden. Thus, multiple phagocytic receptors may be required to perform various cellular processes during efferocytosis. Recently, several receptors have been proposed to act cooperatively for efferocytosis. Stabilin-2 associates with integrin $\alpha v \beta 5$ through its FAS1 domain and functions cooperatively for apoptotic cell engulfment. ${ }^{100}$ In peritoneal macrophages, Tim-4 functions as a tethering receptor for adhesion between apoptotic cells and macrophages, and Mer-TK acts as a tickling receptor to transduce signals for cytoskeletal rearrangement. ${ }^{58}$ During the engulfment of apoptotic neurons, BAI1 is involved in the formation and transport of phagosomes, whereas Tim-4 contributes to phagosome stabilization. ${ }^{62}$ Third, particular types of phagocytic machinery for phosphatidylserine recognition may be required for the efficient efferocytosis of specific phagocytes or under specific conditions. For example, Tim-4 is indispensable for tissue homeostasis in resident peritoneal macrophages, whereas MFG-E8 is essential for apoptotic cell clearance in inflammatory macrophages. ${ }^{101}$ Mer-TK is activated by Gas6 or protein $S$ and acts as a receptor for the maintenance of self-tolerance in resting macrophages. In contrast, Axl is activated by only Gas6 under inflammatory conditions and acts as a receptor for immune suppression. ${ }^{93}$

\section{SIGNALING FOR APOPTOTIC CELL ENGULFMENT}

\section{Signaling pathways for cytoskeletal rearrangement}

Genetic analyses in Caenorhabditis elegans identified three signaling pathways that mediate apoptotic cell clearance: (1) the CED-1, 6 and 7 pathway; (2) the CED-2, 5, and 12 pathway; and (3) the ABI-1 and ABL-1 pathway. ${ }^{102-105}$ In the first pathway, multiple EGF-like domains 10 (MEGF10) and Jedi (also referred to as MEGF12), mammalian homologs of CED-1, act as phagocytic receptors for apoptotic cell clearance. ${ }^{106,107}$ MEGF10 indirectly recognizes phosphatidylserine on the apoptotic cell surface through the bridging molecule Clq, ${ }^{97}$ whereas the molecular mechanism by which apoptotic cells are recognized by Jedi remains to be studied. MEGF10 and Jedi bind to Gulp1 (phosphotyrosine-binding domain-containing engulfment adaptor protein 1), a mammalian ortholog of CED-6, through an NPxY motif in their cytoplasmic region, leading to the transduction of a signal for cytoskeletal rearrangement. ${ }^{108,109} \mathrm{ABCA1}$ and ABCA7, mammalian orthologs of CED-7, are members of the ATP-binding cassette containing transporter family that transport a variety of substances across the plasma membrane. They are involved in apoptotic cell clearance through unknown mechanisms. ${ }^{110,111}$ ABCA1 also has multiple functions in apoptotic cells and phagocytes during efferocytosis, including the release of 'find-me' signals, protection from oxidative stress-induced apoptosis, and enhancement of cholesterol efflux. ${ }^{4,25,108,112}$ The Gulp1 signaling pathway converges on Rac1 (an ortholog of Caenorhabditis elegans CED-10 ${ }^{113}$ and is the downstream signaling pathway through which several phagocytic receptors, such as low-density lipoprotein receptor-related protein-1, Stabilin-1 and Stabilin-2, regulate apoptotic cell engulfment. ${ }^{114-116}$ Stabilin-2 is known to coordinate the activities of the two phagocytic pathways (the Gulp1 pathway and ELMO1/DOCK180 pathway) through a direct interaction with integrin $\alpha v \beta 5 .{ }^{100}$ However, the intermediates between Gulp1 and Racl in this pathway are largely unknown. In the second pathway, the mammalian homologs of CED-2, 5 and 12 are CrkII, DOCK180 and ELMO1, respectively. CrkII associates with DOCK180, a guanine-nucleotide exchange factor, which in turn triggers Racl activation. ${ }^{117}$ ELMO1 associates with DOCK180 and acts as a positive regulator of Racl activation in Caenorhabditis elegans and mammalian cells. $^{118,119}$ In addition, TRIO/UNC-73 and RhoG/MIG-2 signaling also contribute to DOCK180-mediated Rac1 activation for proper phagocytosis. ${ }^{120}$ This pathway is downstream of the PS-receptor BAI1 as well as integrin $\alpha v \beta 5 .{ }^{60,117}$ In the third signaling pathway, ABI-1 (Abi) promotes apoptotic cell clearance through regulation of Rac-1 activity or an independent pathway. ABL-1 interacts with $\mathrm{ABI}-1$ and negatively regulates engulfment by inhibiting ABI- $1 .{ }^{121}$ However, the role 
of the mammalian counterparts of the genes involved in this pathway remains to be defined.

\section{Other signaling pathway during apoptotic cell engulfment} Signaling of the tumor suppressor p53 is shown to regulate apoptotic cell engulfment. p53 controls phagocytosis of apoptotic cells by regulating the expression of death domain $1 \alpha .{ }^{122}$ Death domain $1 \alpha$ is an immunoglobulin superfamily receptor that mediates homophilic interactions between apoptotic cells and phagocytes, leading to the removal of apoptotic cells. The phosphatidylserine receptor BAI1 is also a specific target of p53 in the brain. ${ }^{61}$ However, the molecular mechanism by which p53 signaling is activated in phagocytes remains to be defined. Several factors that can regulate cellular metabolic processes have been proposed as modulators for efferocytosis. Uncoupled protein 2, which reduces mitochondrial membrane potential in cells through uncoupling oxidative phosphorylation from ATP generation, has been shown to positively regulate the engulfment capacity of phagocytes. ${ }^{123}$ Peroxisome proliferator-activated receptors and liver X receptors are activated by the engagement of apoptotic cell and regulate apoptotic cell engulfment, likely increasing the expression of phagocytic receptors or bridging molecules. ${ }^{124-126}$ The nuclear receptor $\mathrm{Nr} 4 \mathrm{al}$ contributes to anti-inflammatory effects during apoptotic cell phagocytosis. ${ }^{127}$ These findings suggest that apoptotic cell clearance is associated with metabolic processes. However, it remains to be seen how the recognition of apoptotic cells activates nuclear receptors.

\section{CONCLUSIONS}

Apoptosis and efferocytosis are processes for homeostatic cell turnover in multicellular organisms, and proper corpse clearance is important to prevent inappropriate inflammatory responses such as autoimmunity. Over the past two decades, numerous studies have been performed to unveil the molecular mechanisms of apoptotic cell clearance, leading to a significant increase in our knowledge of this area. However, multiple unanswered questions concerning clearance mechanisms remain. Why are multiple phagocytic components necessary for efferocytosis? What is the signaling cascade mediated by receptors for engulfment signals? Can particular engulfment signals or phagocytic mechanisms determine immunogenic or tolerogenic clearance of apoptotic cells? To answer these questions, further understanding of engulfment signals and the phagocytic machinery is required. Furthermore, defective clearance of apoptotic cells in tissues is associated with the pathogenesis of various diseases, including autoimmune diseases, chronic obstructive pulmonary disease, atherosclerosis, Alzheimer's disease and cancer. ${ }^{128}$ Thus, an understanding of the precise mechanism of apoptotic cell engulfment could be useful for the development of therapeutic strategies for controlling diseases associated with defective efferocytosis.

\section{CONFLICT OF INTEREST}

The authors declare no conflict of interest.

\section{ACKNOWLEDGEMENTS}

This study was supported by a grant from the National R\&D Program for Cancer Control, Ministry of Health and Welfare, Republic of Korea (1420390); by the Basic Science Research Program through the National Research Foundation of Korea (NRF) funded by the Ministry of Education, Science, and Technology (NRF-2014R1A1A4A01005556); by the Dongguk University Research Fund of 2016; and by the KIST Institutional Program (Project No 2E26320).

1 deCathelineau AM, Henson PM. The final step in programmed cell death: phagocytes carry apoptotic cells to the grave. Essays Biochem 2003; 39: 105-117.

2 Peter C, Waibel M, Radu CG, Yang LV, Witte ON, Schulze-Osthoff K et al. Migration to apoptotic 'find-me' signals is mediated via the phagocyte receptor G2A. J Biol Chem 2008; 283: 5296-5305.

3 Lauber K, Bohn E, Krober SM, Xiao YJ, Blumenthal SG, Lindemann RK et al. Apoptotic cells induce migration of phagocytes via caspase-3mediated release of a lipid attraction signal. Cell 2003; 113: 717-730.

4 Peter C, Waibel M, Keppeler H, Lehmann R, Xu G, Halama A et al. Release of lysophospholipid 'find-me' signals during apoptosis requires the ATP-binding cassette transporter A1. Autoimmunity 2012; 45: 568-573.

5 Truman LA, Ford CA, Pasikowska M, Pound JD, Wilkinson SJ, Dumitriu IE et al. CX3CL1/fractalkine is released from apoptotic lymphocytes to stimulate macrophage chemotaxis. Blood 2008; 112: 5026-5036.

6 Gude DR, Alvarez SE, Paugh SW, Mitra P, Yu J, Griffiths R et al. Apoptosis induces expression of sphingosine kinase 1 to release sphingosine-1phosphate as a 'come-and-get-me' signal. FASEB J 2008; 22: 2629-2638.

7 Elliott MR, Chekeni FB, Trampont PC, Lazarowski ER, Kadl A, Walk SF et al. Nucleotides released by apoptotic cells act as a find-me signal to promote phagocytic clearance. Nature 2009; 461: 282-286.

8 Chekeni FB, Elliott MR, Sandilos JK, Walk SF, Kinchen JM, Lazarowski ER et al. Pannexin 1 channels mediate 'find-me' signal release and membrane permeability during apoptosis. Nature 2010; 467: 863-867.

9 Leonardi-Essmann F, Emig M, Kitamura Y, Spanagel R, Gebicke-Haerter PJ. Fractalkine-upregulated milk-fat globule EGF factor-8 protein in cultured rat microglia. J Neuroimmunol 2005; 160: 92-101.

10 Miksa M, Amin D, Wu R, Ravikumar TS, Wang P. Fractalkine-induced MFG-E8 leads to enhanced apoptotic cell clearance by macrophages. Mol Med 2007; 13: 553-560.

11 Weigert A, Johann AM, von Knethen A, Schmidt H, Geisslinger G, Brune B. Apoptotic cells promote macrophage survival by releasing the antiapoptotic mediator sphingosine-1-phosphate. Blood 2006; 108: 1635-1642.

12 Luo B, Gan W, Liu Z, Shen Z, Wang J, Shi R et al. Erythropoeitin signaling in macrophages promotes dying cell clearance and immune tolerance. Immunity 2016; 44: 287-302.

13 Fadok VA, Voelker DR, Campbell PA, Cohen JJ, Bratton DL, Henson PM. Exposure of phosphatidylserine on the surface of apoptotic lymphocytes triggers specific recognition and removal by macrophages. I Immunol 1992; 148: 2207-2216.

14 van den Eijnde SM, Boshart L, Baehrecke EH, De Zeeuw $\mathrm{Cl}$, Reutelingsperger CP, Vermeij-Keers C. Cell surface exposure of phosphatidylserine during apoptosis is phylogenetically conserved. Apoptosis 1998; 3: 9-16.

15 Venegas V, Zhou Z. Two alternative mechanisms that regulate the presentation of apoptotic cell engulfment signal in Caenorhabditis elegans. Mol Biol Cell 2007; 18: 3180-3192.

16 Suzuki J, Denning DP, Imanishi E, Horvitz HR, Nagata S. Xk-related protein 8 and CED-8 promote phosphatidylserine exposure in apoptotic cells. Science 2013; 341: 403-406.

17 Chen YZ, Mapes J, Lee ES, Skeen-Gaar RR, Xue D. Caspase-mediated activation of Caenorhabditis elegans CED-8 promotes apoptosis and phosphatidylserine externalization. Nat Commun 2013; 4: 2726.

18 Suzuki J, Imanishi E, Nagata S. Xkr8 phospholipid scrambling complex in apoptotic phosphatidylserine exposure. Proc Natl Acad Sci USA 2016; 113: 9509-9514. 
19 Segawa K, Kurata S, Yanagihashi Y, Brummelkamp TR, Matsuda F, Nagata S. Caspase-mediated cleavage of phospholipid flippase for apoptotic phosphatidylserine exposure. Science 2014; 344 1164-1168.

20 Panaretakis T, Kepp O, Brockmeier U, Tesniere A, Bjorklund AC, Chapman DC et al. Mechanisms of pre-apoptotic calreticulin exposure in immunogenic cell death. EMBO J 2009; 28: 578-590.

21 Gardai SJ, McPhillips KA, Frasch SC, Janssen WJ, Starefeldt A, Murphy-Ullrich JE et al. Cell-surface calreticulin initiates clearance of viable or apoptotic cells through trans-activation of LRP on the phagocyte. Cell 2005; 123: 321-334.

22 Wijeyesakere SJ, Bedi SK, Huynh D, Raghavan M. The C-terminal acidic region of calreticulin mediates phosphatidylserine binding and apoptotic cell phagocytosis. J Immunol 2016; 196: 3896-3909.

23 Obeid M, Tesniere A, Ghiringhelli F, Fimia GM, Apetoh L, Perfettini JL et al. Calreticulin exposure dictates the immunogenicity of cancer cell death. Nat Med 2007; 13: 54-61.

24 Feng M, Chen JY, Weissman-Tsukamoto R, Volkmer JP, Ho PY, McKenna KM et al. Macrophages eat cancer cells using their own calreticulin as a guide: roles of TLR and Btk. Proc Natl Acad Sci USA 2015; 112: 2145-2150.

25 Kiss RS, Elliott MR, Ma Z, Marcel YL, Ravichandran KS. Apoptotic cells induce a phosphatidylserine-dependent homeostatic response from phagocytes. Curr Biol 2006; 16: 2252-2258.

26 Huynh ML, Fadok VA, Henson PM. Phosphatidylserine-dependent ingestion of apoptotic cells promotes TGF-betal secretion and the resolution of inflammation. J Clin Invest 2002; 109: 41-50.

27 Oldenborg PA, Zheleznyak A, Fang YF, Lagenaur CF, Gresham HD, Lindberg FP. Role of CD47 as a marker of self on red blood cells. Science 2000; 288: 2051-2054.

28 Lv Z, Bian Z, Shi L, Niu S, Ha B, Tremblay A et al. Loss of cell surface CD47 clustering formation and binding avidity to SIRPalpha facilitate apoptotic cell clearance by macrophages. J Immunol 2015; 195: 661-671.

29 Jaiswal S, Jamieson CH, Pang WW, Park CY, Chao MP, Majeti R et al. CD47 is upregulated on circulating hematopoietic stem cells and leukemia cells to avoid phagocytosis. Cell 2009; 138: 271-285.

30 Majeti R, Chao MP, Alizadeh AA, Pang WW, Jaiswal S, Gibbs KD Jr et al. CD47 is an adverse prognostic factor and therapeutic antibody target on human acute myeloid leukemia stem cells. Cell 2009; 138: 286-299.

31 Weiskopf K, Ring AM, Ho CC, Volkmer JP, Levin AM, Volkmer AK et al. Engineered SIRPalpha variants as immunotherapeutic adjuvants to anticancer antibodies. Science 2013; 341: 88-91.

32 Tseng D, Volkmer JP, Willingham SB, Contreras-Trujillo H, Fathman JW, Fernhoff NB et al. Anti-CD47 antibody-mediated phagocytosis of cancer by macrophages primes an effective antitumor T-cell response. Proc Natl Acad Sci USA 2013; 110: 11103-11108.

33 Liu X, Pu Y, Cron K, Deng L, Kline J, Frazier WA et al. CD47 blockade triggers $\mathrm{T}$ cell-mediated destruction of immunogenic tumors. Nat Med 2015; 21: 1209-1215.

34 Brown S, Heinisch I, Ross E, Shaw K, Buckley CD, Savill J. Apoptosis disables CD31-mediated cell detachment from phagocytes promoting binding and engulfment. Nature 2002; 418: 200-203.

35 Tkach M, Thery C. Communication by extracellular vesicles: where we are and where we need to go. Cell 2016; 164: 1226-1232.

36 Torr EE, Gardner DH, Thomas L, Goodall DM, Bielemeier A, Willetts R et al. Apoptotic cell-derived ICAM-3 promotes both macrophage chemoattraction to and tethering of apoptotic cells. Cell Death Differ 2012; 19: 671-679.

37 Tsai WH, Shih CH, Feng SY, Li IT, Chang SC, Lin YC et al. CX3CL1(+) microparticles mediate the chemoattraction of alveolar macrophages toward apoptotic acute promyelocytic leukemic cells. Cell Physiol Biochem 2014; 33: 594-604.

38 Eguchi A, Mulya A, Lazic M, Radhakrishnan D, Berk MP, Povero D et al. Microparticles release by adipocytes act as 'find-me' signals to promote macrophage migration. PLOS ONE 2015; 10: e0123110.

39 Niessen A, Heyder P, Krienke S, Blank N, Tykocinski LO, Lorenz HM et al. Apoptotic-cell-derived membrane microparticles and IFN-alpha induce an inflammatory immune response. J Cell Sci 2015; 128: 2443-2453.

40 Sisirak V, Sally B, D'Agati V, Martinez-Ortiz W, Ozcakar ZB, David J et al. Digestion of chromatin in apoptotic cell microparticles prevents autoimmunity. Cell 2016; 166: 88-101.
41 Garzetti L, Menon R, Finardi A, Bergami A, Sica A, Martino G et al. Activated macrophages release microvesicles containing polarized $\mathrm{M} 1$ or M2 mRNAs. J Leukoc Biol 2014; 95: 817-825.

42 Han CZ, Juncadella IJ, Kinchen JM, Buckley MW, Klibanov AL, Dryden K et al. Macrophages redirect phagocytosis by non-professional phagocytes and influence inflammation. Nature 2016; 539: 570-574.

43 Xu Y, Liu Y, Yang C, Kang L, Wang M, Hu J et al. Macrophages transfer antigens to dendritic cells by releasing exosomes containing dead-cellassociated antigens partially through a ceramide-dependent pathway to enhance CD4(+) T-cell responses. Immunology 2016; 149: 157-171.

44 Bournazou I, Pound JD, Duffin R, Bournazos S, Melville LA, Brown SB et al. Apoptotic human cells inhibit migration of granulocytes via release of lactoferrin. J Clin Invest 2009; 119: 20-32.

45 Bournazou I, Mackenzie KJ, Duffin R, Rossi AG, Gregory CD. Inhibition of eosinophil migration by lactoferrin. Immunol Cell Biol 2010; 88: 220-223.

46 Arur S, Uche UE, Rezaul K, Fong M, Scranton V, Cowan AE et al. Annexin $\mathrm{I}$ is an endogenous ligand that mediates apoptotic cell engulfment. Dev Cell 2003; 4: 587-598.

47 Weyd H, Abeler-Dorner L, Linke B, Mahr A, Jahndel V, Pfrang S et al. Annexin $\mathrm{A} 1$ on the surface of early apoptotic cells suppresses CD8+ T cell immunity. PLOS ONE 2013; 8: e62449.

48 Linke B, Abeler-Dorner L, Jahndel V, Kurz A, Mahr A, Pfrang S et al. The tolerogenic function of annexins on apoptotic cells is mediated by the annexin core domain. J Immunol 2015; 194: 5233-5242.

49 Uderhardt S, Herrmann M, Oskolkova OV, Aschermann S, Bicker W, Ipseiz N et al. 12/15-lipoxygenase orchestrates the clearance of apoptotic cells and maintains immunologic tolerance. Immunity 2012; 36: 834-846.

50 Miyanishi M, Tada K, Koike M, Uchiyama Y, Kitamura T, Nagata S. Identification of Tim4 as a phosphatidylserine receptor. Nature 2007; 450: 435-439.

51 Kobayashi N, Karisola P, Pena-Cruz V, Dorfman DM, Jinushi M, Umetsu SE et al. TIM-1 and TIM-4 glycoproteins bind phosphatidylserine and mediate uptake of apoptotic cells. Immunity 2007; 27: 927-940.

52 Nakayama M, Akiba H, Takeda K, Kojima Y, Hashiguchi M, Azuma M et al. Tim-3 mediates phagocytosis of apoptotic cells and crosspresentation. Blood 2009; 113: 3821-3830.

53 Santiago C, Ballesteros A, Martinez-Munoz L, Mellado M, Kaplan GG, Freeman GJ et al. Structures of T cell immunoglobulin mucin protein 4 show a metal-ion-dependent ligand binding site where phosphatidylserine binds. Immunity 2007; 27: 941-951.

54 Ichimura T, Asseldonk EJ, Humphreys BD, Gunaratnam L, Duffield JS, Bonventre JV. Kidney injury molecule-1 is a phosphatidylserine receptor that confers a phagocytic phenotype on epithelial cells. J Clin Invest 2008; 118: 1657-1668.

55 Yang L, Brooks CR, Xiao S, Sabbisetti V, Yeung MY, Hsiao LL et al. KIM-1mediated phagocytosis reduces acute injury to the kidney. J Clin Invest 2015; 125: 1620-1636.

56 Albacker LA, Karisola P, Chang YJ, Umetsu SE, Zhou M, Akbari $O$ et al. TIM-4, a receptor for phosphatidylserine, controls adaptive immunity by regulating the removal of antigen-specific T cells. J Immunol 2010; 185: 6839-6849.

57 Park D, Hochreiter-Hufford A, Ravichandran KS. The phosphatidylserine receptor TIM-4 does not mediate direct signaling. Curr Biol 2009; 19 : 346-351.

58 Nishi C, Toda S, Segawa K, Nagata S. Tim4- and MerTK-mediated engulfment of apoptotic cells by mouse resident peritoneal macrophages. Mol Cell Biol 2014; 34: 1512-1520.

59 Flannagan RS, Canton J, Furuya W, Glogauer M, Grinstein S. The phosphatidylserine receptor TIM4 utilizes integrins as coreceptors to effect phagocytosis. Mol Biol Cell 2014; 25: 1511-1522.

60 Park D, Tosello-Trampont AC, Elliott MR, Lu M, Haney LB, Ma Z et al. BAI1 is an engulfment receptor for apoptotic cells upstream of the ELMO/ Dock180/Rac module. Nature 2007; 450: 430-434.

61 Mori K, Kanemura Y, Fujikawa H, Nakano A, Ikemoto H, Ozaki I et al. Brain-specific angiogenesis inhibitor 1 (BAI1) is expressed in human cerebral neuronal cells. Neurosci Res 2002; 43: 69-74.

62 Mazaheri F, Breus O, Durdu S, Haas P, Wittbrodt J, Gilmour D et al. Distinct roles for BAI1 and TIM-4 in the engulfment of dying neurons by microglia. Nat Commun 2014; 5: 4046.

63 Hochreiter-Hufford AE, Lee CS, Kinchen JM, Sokolowski JD, Arandjelovic S, Call JA et al. Phosphatidylserine receptor BAI1 and apoptotic cells as new promoters of myoblast fusion. Nature 2013; 497: 263-267. 
64 Hamoud N, Tran V, Croteau LP, Kania A, Cote JF. G-protein coupled receptor BAI3 promotes myoblast fusion in vertebrates. Proc Natl Acad Sci USA 2014; 111: 3745-3750.

65 Park SY, Jung MY, Kim HJ, Lee SJ, Kim SY, Lee BH et al. Rapid cell corpse clearance by stabilin-2, a membrane phosphatidylserine receptor. Cell Death Differ 2008; 15: 192-201.

66 Park SY, Kim SY, Jung MY, Bae DJ, Kim IS. Epidermal growth factor-like domain repeat of stabilin-2 recognizes phosphatidylserine during cell corpse clearance. Mol Cell Biol 2008; 28: 5288-5298.

67 Kim S, Bae DJ, Hong M, Park SY, Kim IS. The conserved histidine in epidermal growth factor-like domains of stabilin-2 modulates $\mathrm{pH}$-dependent recognition of phosphatidylserine in apoptotic cells. Int $J$ Biochem Cell Biol 2010; 42: 1154-1163.

68 Park SY, Jung MY, Lee SJ, Kang KB, Gratchev A, Riabov V et al. Stabilin-1 mediates phosphatidylserine-dependent clearance of cell corpses in alternatively activated macrophages. J Cell Sci 2009; 122: 3365-3373.

69 Zhou B, Weigel JA, Fauss L, Weigel PH. Identification of the hyaluronan receptor for endocytosis (HARE). J Biol Chem 2000; 275: 37733-37741.

70 Qian H, Johansson S, McCourt P, Smedsrod B, Ekblom M. Stabilins are expressed in bone marrow sinusoidal endothelial cells and mediate scavenging and cell adhesive functions. Biochem Biophys Res Commun 2009; 390: 883-886.

71 Kzhyshkowska J, Gratchev A, Goerdt S. Stabilin-1, a homeostatic scavenger receptor with multiple functions. J Cell Mol Med 2006; 10: 635-649.

72 Lee SJ, Park SY, Jung MY, Bae SM, Kim IS. Mechanism for phosphatidylserine-dependent erythrophagocytosis in mouse liver. Blood 2011; 117: 5215-5223.

73 Murakami Y, Tian L, Voss OH, Margulies DH, Krzewski K, Coligan JE. CD300b regulates the phagocytosis of apoptotic cells via phosphatidylserine recognition. Cell Death Differ 2014; 21: 1746-1757.

74 Choi SC, Simhadri VR, Tian L, Gil-Krzewska A, Krzewski K, Borrego F et al. Cutting edge: mouse CD300f (CMRF-35-like molecule-1) recognizes outer membrane-exposed phosphatidylserine and can promote phagocytosis. J Immunol 2011; 187: 3483-3487.

75 Tian L, Choi SC, Murakami Y, Allen J, Morse HC 3rd, Qi CF et al. p85alpha recruitment by the CD300f phosphatidylserine receptor mediates apoptotic cell clearance required for autoimmunity suppression. Nat Commun 2014; 5: 3146.

76 Simhadri VR, Andersen JF, Calvo E, Choi SC, Coligan JE, Borrego F. Human CD300a binds to phosphatidylethanolamine and phosphatidylserine, and modulates the phagocytosis of dead cells. Blood 2012; 119: 2799-2809.

77 He M, Kubo H, Morimoto K, Fujino N, Suzuki T, Takahasi T et al. Receptor for advanced glycation end products binds to phosphatidylserine and assists in the clearance of apoptotic cells. EMBO Rep 2011; 12: 358-364.

78 Greenberg ME, Sun M, Zhang R, Febbraio M, Silverstein R, Hazen SL. Oxidized phosphatidylserine-CD36 interactions play an essential role in macrophage-dependent phagocytosis of apoptotic cells. J Exp Med 2006; 203: 2613-2625.

79 Fadok VA, Warner ML, Bratton DL, Henson PM. CD36 is required for phagocytosis of apoptotic cells by human macrophages that use either a phosphatidylserine receptor or the vitronectin receptor (alpha $v$ beta 3 ). J Immunol 1998; 161: 6250-6257.

80 Devitt A, Moffatt OD, Raykundalia C, Capra JD, Simmons DL, Gregory CD. Human CD14 mediates recognition and phagocytosis of apoptotic cells. Nature 1998; 392: 505-509.

81 Devitt A, Parker KG, Ogden CA, Oldreive C, Clay MF, Melville LA et al. Persistence of apoptotic cells without autoimmune disease or inflammation in CD14-/- mice. J Cell Biol 2004; 167: 1161-1170.

82 Hanayama R, Tanaka M, Miwa K, Shinohara A, Iwamatsu A, Nagata S. Identification of a factor that links apoptotic cells to phagocytes. Nature 2002; 417: 182-187.

83 Akakura S, Singh S, Spataro M, Akakura R, Kim JI, Albert ML et al. The opsonin MFG-E8 is a ligand for the alphavbeta5 integrin and triggers DOCK180-dependent Rac1 activation for the phagocytosis of apoptotic cells. Exp Cell Res 2004; 292: 403-416.

84 Anderson HA, Maylock CA, Williams JA, Paweletz CP, Shu H, Shacter E. Serum-derived protein $S$ binds to phosphatidylserine and stimulates the phagocytosis of apoptotic cells. Nat Immunol 2003; 4: 87-91.
85 Ishimoto Y, Ohashi K, Mizuno K, Nakano T. Promotion of the uptake of PS liposomes and apoptotic cells by a product of growth arrest-specific gene, gas6. J Biochem 2000; 127: 411-417.

86 Sasaki T, Knyazev PG, Cheburkin Y, Gohring W, Tisi D, Ullrich A et al. Crystal structure of a C-terminal fragment of growth arrest-specific protein Gas6. Receptor tyrosine kinase activation by laminin G-like domains. J Biol Chem 2002; 277: 44164-44170.

87 Uehara H, Shacter E. Auto-oxidation and oligomerization of protein S on the apoptotic cell surface is required for Mer tyrosine kinase-mediated phagocytosis of apoptotic cells. J Immunol 2008; 180: 2522-2530.

88 Scott RS, McMahon EJ, Pop SM, Reap EA, Caricchio R, Cohen PL et al. Phagocytosis and clearance of apoptotic cells is mediated by MER. Nature 2001; 411: 207-211.

89 Wu Y, Singh S, Georgescu MM, Birge RB. A role for Mer tyrosine kinase in alphavbeta5 integrin-mediated phagocytosis of apoptotic cells. J Cell Sci 2005; 118: 539-553.

90 Todt JC, Hu B, Curtis JL. The scavenger receptor SR-A I/II (CD204) signals via the receptor tyrosine kinase Mertk during apoptotic cell uptake by murine macrophages. J Leukoc Biol 2008; 84: 510-518.

91 Caberoy NB, Alvarado G, Bigcas JL, Li W. Galectin-3 is a new MerTKspecific eat-me signal. J Cell Physiol 2012; 227: 401-407.

92 Wallet MA, Sen P, Flores RR, Wang Y, Yi Z, Huang Y et al. MerTK is required for apoptotic cell-induced $\mathrm{T}$ cell tolerance. J Exp Med 2008; 205: 219-232.

93 Zagorska A, Traves PG, Lew ED, Dransfield I, Lemke G. Diversification of TAM receptor tyrosine kinase function. Nat Immunol 2014; 15: 920-928.

94 Paidassi H, Tacnet-Delorme P, Garlatti V, Darnault C, Ghebrehiwet B, Gaboriaud $\mathrm{C}$ et al. C1q binds phosphatidylserine and likely acts as a multiligand-bridging molecule in apoptotic cell recognition. J Immunol 2008; 180: 2329-2338.

95 Ogden CA, deCathelineau A, Hoffmann PR, Bratton D, Ghebrehiwet B, Fadok VA et al. C1q and mannose binding lectin engagement of cell surface calreticulin and CD91 initiates macropinocytosis and uptake of apoptotic cells. J Exp Med 2001; 194: 781-795.

96 Ramirez-Ortiz ZG, Pendergraft WF 3rd, Prasad A, Byrne MH, Iram T, Blanchette CJ et al. The scavenger receptor SCARF1 mediates the clearance of apoptotic cells and prevents autoimmunity. Nat Immunol 2013; 14: 917-926.

97 Iram T, Ramirez-Ortiz Z, Byrne MH, Coleman UA, Kingery ND, Means TK et al. Megf10 is a receptor for $\mathrm{C} 1 \mathrm{Q}$ that mediates clearance of apoptotic cells by astrocytes. J Neurosci 2016; 36: 5185-5192.

98 Galvan MD, Foreman DB, Zeng E, Tan JC, Bohlson SS. Complement component $\mathrm{Clq}$ regulates macrophage expression of Mer tyrosine kinase to promote clearance of apoptotic cells. J Immunol 2012; 188: 3716-3723.

99 Schlegel RA, Williamson P. Phosphatidylserine, a death knell. Cell Death Differ 2001; 8: 551-563.

100 Kim S, Park SY, Kim SY, Bae DJ, Pyo JH, Hong M et al. Cross talk between engulfment receptors stabilin-2 and integrin alphavbeta5 orchestrates engulfment of phosphatidylserine-exposed erythrocytes. $\mathrm{Mol} \mathrm{Cell}$ Biol 2012; 32: 2698-2708.

101 Wong K, Valdez PA, Tan C, Yeh S, Hongo JA, Ouyang W. Phosphatidylserine receptor Tim-4 is essential for the maintenance of the homeostatic state of resident peritoneal macrophages. Proc Natl Acad Sci USA 2010; 107: 8712-8717.

102 Wu YC, Horvitz HR. C. elegans phagocytosis and cell-migration protein CED-5 is similar to human DOCK180. Nature 1998; 392: 501-504.

103 Wu YC, Horvitz HR. The $C$. elegans cell corpse engulfment gene ced-7 encodes a protein similar to ABC transporters. Cell 1998; 93: 951-960.

104 Reddien PW, Horvitz HR. CED-2/Crkll and CED-10/Rac control phagocytosis and cell migration in Caenorhabditis elegans. Nat Cell Biol 2000; 2: 131-136.

105 Liu QA, Hengartner MO. Candidate adaptor protein CED-6 promotes the engulfment of apoptotic cells in C. elegans. Cell 1998; 93: 961-972.

106 Wu HH, Bellmunt E, Scheib JL, Venegas V, Burkert C, Reichardt LF et al. Glial precursors clear sensory neuron corpses during development via Jedi-1, an engulfment receptor. Nat Neurosci 2009; 12: 1534-1541.

107 Scheib JL, Sullivan CS, Carter BD. Jedi-1 and MEGF10 signal engulfment of apoptotic neurons through the tyrosine kinase Syk. J Neurosci 2012; 32: $13022-13031$.

108 Hamon Y, Trompier D, Ma Z, Venegas V, Pophillat M, Mignotte V et al. Cooperation between engulfment receptors: the case of ABCA1 and MEGF10. PLOS ONE 2006; 1: e120. 
109 Sullivan CS, Scheib JL, Ma Z, Dang RP, Schafer JM, Hickman FE et al. The adaptor protein GULP promotes Jedi-1-mediated phagocytosis through a clathrin-dependent mechanism. Mol Biol Cell 2014; 25: 1925-1936.

110 Jehle AW, Gardai SJ, Li S, Linsel-Nitschke P, Morimoto K, Janssen WJ et al. ATP-binding cassette transporter A7 enhances phagocytosis of apoptotic cells and associated ERK signaling in macrophages. J Cell Biol 2006; 174: 547-556.

111 Hamon Y, Broccardo C, Chambenoit O, Luciani MF, Toti F, Chaslin S et al. $\mathrm{ABC} 1$ promotes engulfment of apoptotic cells and transbilayer redistribution of phosphatidylserine. Nat Cell Biol 2000; 2: 399-406.

112 Yvan-Charvet L, Pagler TA, Seimon TA, Thorp E, Welch CL, Witztum JL et al. $A B C A 1$ and $A B C G 1$ protect against oxidative stress-induced macrophage apoptosis during efferocytosis. Circ Res 2010; 106: 1861-1869.

113 Kinchen JM, Cabello J, Klingele D, Wong K, Feichtinger R, Schnabel H et al. Two pathways converge at CED-10 to mediate actin rearrangement and corpse removal in C. elegans. Nature 2005; 434: 93-99.

114 Park SY, Kang KB, Thapa N, Kim SY, Lee SJ, Kim IS. Requirement of adaptor protein GULP during stabilin-2-mediated cell corpse engulfment. J Biol Chem 2008; 283: 10593-10600.

115 Su HP, Nakada-Tsukui K, Tosello-Trampont AC, Li Y, Bu G, Henson PM et al. Interaction of CED-6/GULP, an adapter protein involved in engulfment of apoptotic cells with CED-1 and CD91/low density lipoprotein receptor-related protein (LRP). J Biol Chem 2002; 277: 11772-11779.

116 Park SY, Kim SY, Kang KB, Kim IS. Adaptor protein GULP is involved in stabilin-1-mediated phagocytosis. Biochem Biophys Res Commun 2010; 398: 467-472.

117 Albert ML, Kim JI, Birge RB. alphavbeta5 integrin recruits the CrkllDock180-rac1 complex for phagocytosis of apoptotic cells. Nat Cell Biol 2000; 2: 899-905.

118 Gumienny TL, Brugnera E, Tosello-Trampont AC, Kinchen JM, Haney LB, Nishiwaki K et al. CED-12/ELMO, a novel member of the Crkll/Dock180/ Rac pathway, is required for phagocytosis and cell migration. Cell 2001; 107: 27-41.

119 Wu YC, Tsai MC, Cheng LC, Chou CJ, Weng NY. C. elegans CED-12 acts in the conserved crklI/DOCK180/Rac pathway to control cell migration and cell corpse engulfment. Dev Cell 2001; 1: 491-502.

120 deBakker CD, Haney LB, Kinchen JM, Grimsley C, Lu M, Klingele D et al. Phagocytosis of apoptotic cells is regulated by a UNC-73/TRIO-MIG-2/ RhoG signaling module and armadillo repeats of CED-12/ELMO. Curr Biol 2004; 14: 2208-2216.
121 Hurwitz ME, Vanderzalm PJ, Bloom L, Goldman J, Garriga G, Horvitz HR. Abl kinase inhibits the engulfment of apoptotic [corrected] cells in Caenorhabditis elegans. PLoS Biol 2009; 7: e99.

122 Yoon KW, Byun S, Kwon E, Hwang SY, Chu K, Hiraki M et al. Control of signaling-mediated clearance of apoptotic cells by the tumor suppressor p53. Science 2015; 349: 1261669.

123 Park D, Han CZ, Elliott MR, Kinchen JM, Trampont PC, Das S et al. Continued clearance of apoptotic cells critically depends on the phagocyte Ucp2 protein. Nature 2011; 477: 220-224.

124 Mukundan L, Odegaard JI, Morel CR, Heredia JE, Mwangi JW, Ricardo-Gonzalez RR et al. PPAR-delta senses and orchestrates clearance of apoptotic cells to promote tolerance. Nat Med 2009; 15: 1266-1272.

125 Roszer T, Menendez-Gutierrez MP, Lefterova MI, Alameda D, Nunez V, Lazar MA et al. Autoimmune kidney disease and impaired engulfment of apoptotic cells in mice with macrophage peroxisome proliferator-activated receptor gamma or retinoid $\mathrm{X}$ receptor alpha deficiency. J Immunol 2011; 186: 621-631.

126 A-Gonzalez N, Bensinger SJ, Hong C, Beceiro S, Bradley MN, Zelcer N et al. Apoptotic cells promote their own clearance and immune tolerance through activation of the nuclear receptor LXR. Immunity 2009; 31: 245-258.

127 Ipseiz N, Uderhardt S, Scholtysek C, Steffen M, Schabbauer G, Bozec A et al. The nuclear receptor Nr4a1 mediates anti-inflammatory effects of apoptotic cells. J Immunol 2014; 192: 4852-4858.

128 Poon IK, Lucas CD, Rossi AG, Ravichandran KS. Apoptotic cell clearance: basic biology and therapeutic potential. Nat Rev Immunol 2014; 14: 166-180.

(c) (1) () $\odot$ This work is licensed under a Creative Commons Attribution-NonCommercial-NoDerivs 4.0 International License. The images or other third party material in this article are included in the article's Creative Commons license, unless indicated otherwise in the credit line; if the material is not included under the Creative Commons license, users will need to obtain permission from the license holder to reproduce the material. To view a copy of this license, visit http://creativecommons.org/licenses/by-nc-nd/4.0/ 